\title{
Formulae to Predict Elastic Hoop Stresses across the Transverse Edge of a Large Radial Circular Cross Bore in Thick Cylinders
}

\author{
P. K. NZIU* and L. M. MASU \\ Department of Mechanical Engineering, Vaal University of Technology, South Africa.
}

ORCID: 0000-0002-5899-0700 (Dr PK Nziu), 0000-0002-8544-6321(Prof LM Masu)

\begin{abstract}
This study presents the analyses of analytical solution developed to predict hoop stresses along a transverse edge of large radial circular cross bores. The developed analytical solution was analysed using three large radial circular cross bores with bore ratio of $0.7,0.85$ and 1.0 on thick cylinders having various thickness ratios. The analytical results obtained were then compared with those generated using finite element analysis on cylinders with similar geometric configuration for authentication purposes. Only, at thickness ratios of 1.75 and 2.0 for bore ratio of 0.7 where the hoop stresses predicted by the two approaches converged. An occurrence that was attributed to yielding of the pressure vessels. Yielding of pressure vessels due to the introduction of large cross bore with bore ratio of 0.7 was seen to start from the thickness ratio of 2.25 and beyond. Similarly, that of bore ratios of 0.85 and 1.0 commenced from thickness ratio of 1.75 .
\end{abstract}

Keywords. Thick cylinders, large cross bore, transverse edge, hoop stress, yielding

\section{INTRODUCTION}

Thick cylinders are often used as high pressure vessels to hold large amount of energy (Nziu and Masu, 2020). As a form of structural design, large cross bore such as pipe junction are usually constructed on the wall of the pressure vessels. Usually, a cross bore is referred to as large cross bore whenever its bore ratio (cross bore to main bore ratio) is greater than 0.5 (Nziu and Masu, 2019a).

Various techniques have been used to design pressure vessels, with common ones being analytical (also known as theoretical), experimental and numerical (also known as computational) methods (Masu, 1989). A recent study by Nziu and Masu (2019b) developed analytical solution that is able to predict various types of principal stresses along a transverse edge of a radial circular cross bore. However, only results generated by the hoop stress solution for small circular cross bores (i.e. Cross bore ratio $\leq 0.5$ ) were presented and discussed in the aforementioned study.

In this regard, this study presents results and analyses of hoop stresses for large radial circular cross bores generated from the solution given in Nziu and Masu (2019b) study. Further, the results generated by the analytical solution are compared with those developed using Finite Element Analysis (FEA) for the purposes of validation.

\section{METHODOLOGY}

Stress component in the hoop direction of the main cylinder

In the research work by Nziu and Masu (2019b), the total hoop stress along the cross bore, which is also referred to as the maximum principal stress, was obtained by the summation of all the corresponding hoop stress equations. This summation encompassed equations $1,6,8,12$ and 23 as presented in the aforementioned study. The computation of the total hoop stress $\sigma_{\theta_{\text {Total }}}$ is illustrated in Equation 1.

$$
\begin{aligned}
\sigma_{\theta_{\text {Total }}}= & \frac{p_{i}}{k^{2}-1}\left(1+\left(\frac{R_{0}}{R}\right)^{2}\right) \\
& +\frac{k^{2} m^{2} p_{i}}{k^{4} m^{4} \sin ^{2} \theta-1}\left(1+\frac{R_{0}^{2}}{R^{2}}\right) \\
& +\frac{1}{m^{2}-1}\left[m^{2} \sigma_{z}+p_{i}+m^{2} \frac{R_{i}^{2}}{r^{2}}\left(\sigma_{z}+p_{i}\right)\right] \\
& +\left(2 C+12 D r^{2}+\frac{6 E}{r^{4}}\right) \cos 2 \theta+p_{i}
\end{aligned}
$$

Where

r Arbitrary radius measured from the cross bore bore centre

$p_{i} \quad$ Internal pressure.

$\sigma_{z} \quad$ local longitudinal stress at the surface of the cross bore

$\theta \quad$ Angle between the vertical axis and the small element.

$\mathrm{K}$ Cylinder thickness ratio

$R_{i} \quad$ Internal radius of the main bore.

$R_{O} \quad$ External radius of the main bore.

$r_{i} \quad$ Cross bore radius.

$\mathrm{R}$ Arbitrary radius measured from the main bore centre

m Ratio of $R_{O}$ and $r_{i}$,

\section{Cases studied}

Three large radial circular cross bores with bore ratio of 0.7 , 0.85 and 1.0, having a configuration illustrated in Figure 1 were studied on seven different thick walled cylinders. The actual 
thickness ratios of these cylinders were $1.4,1.5,1.75,2.0,2.25$, 2.5 and 3.0 .

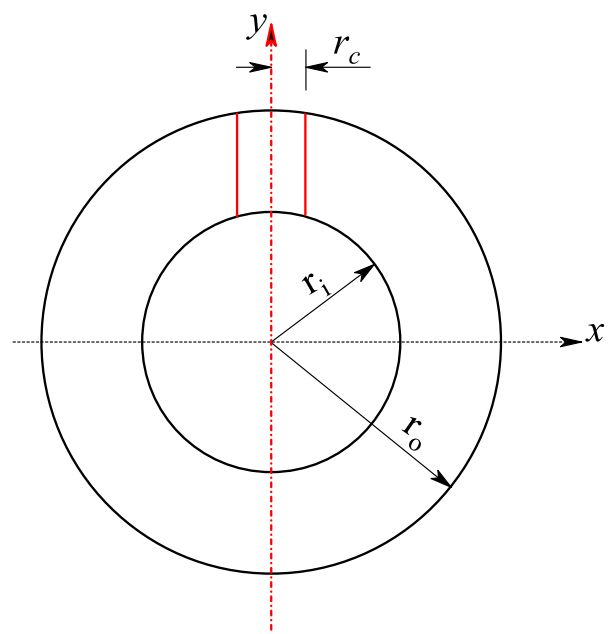

Figure 1 : Cross bore configuration

Where

$r_{c}$ is the radius of the cross bore

$r_{i}$ is the internal radius of the main bore

$r_{0}$ is the external radius of the main bore

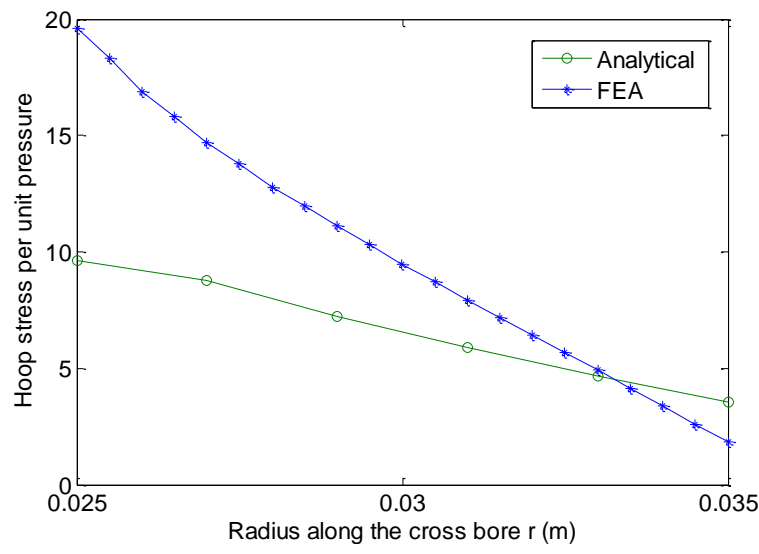

Figure 2: $\mathrm{K}=1.4 \mathrm{CB}=0.7$

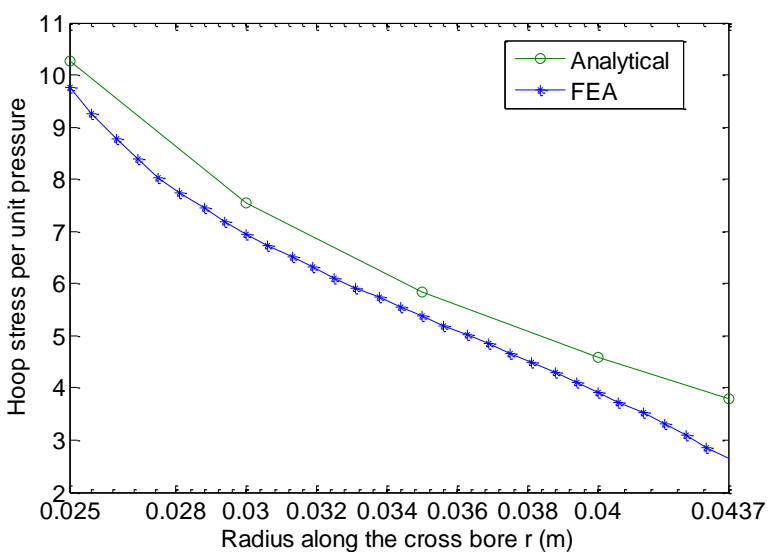

Figure 4: $\mathrm{K}=1.75 \mathrm{CB}=0.7$

\section{Finite Element Analysis}

Finite Element Analysis technique was used to validate the results generated by equation 2 for large circular radial cross bores. A commercial FEA software namely, Abaqus Version 16 was used in this work. The results given by this software were initially revalidated using known solutions from Lame's theory for plain cylinders. After which 21 FEA models with similar geometric outline to those studied in the preceding analytical section were created and analysed. A detailed modelling procedure adopted in this research work is presented in Nziu (2018) doctoral thesis.

\section{RESULTS AND DISCUSSION}

Results generated by the methods described in the methodology section are presented and discussed under the following subheadings:

\section{Cross bore to main bore ratio of 0.7}

Results of high pressure vessels with a main bore to cross bore size ratio of 0.7 are presented in figures $2-8$ for $\mathrm{K}=1.4,1.5$, $1.75,2.0,2.25,2.5$ and 3.0 .

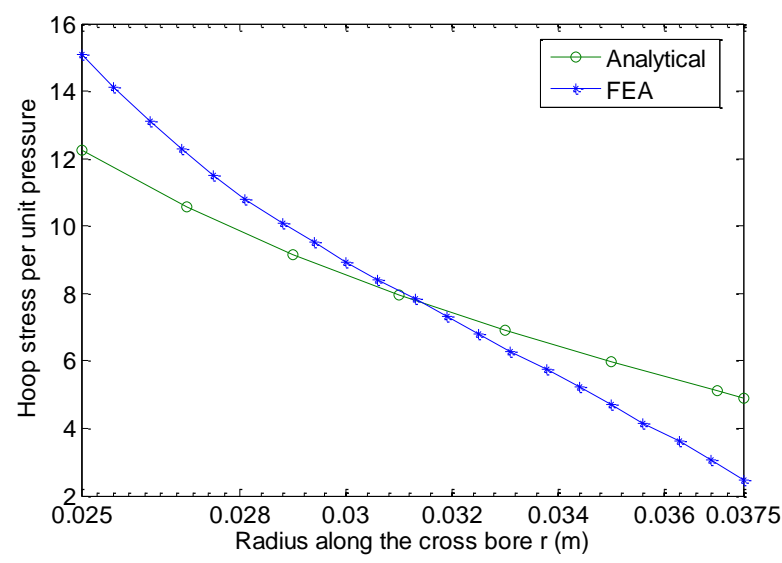

Figure 3: $\mathrm{K}=1.5 \mathrm{CB}=0.7$

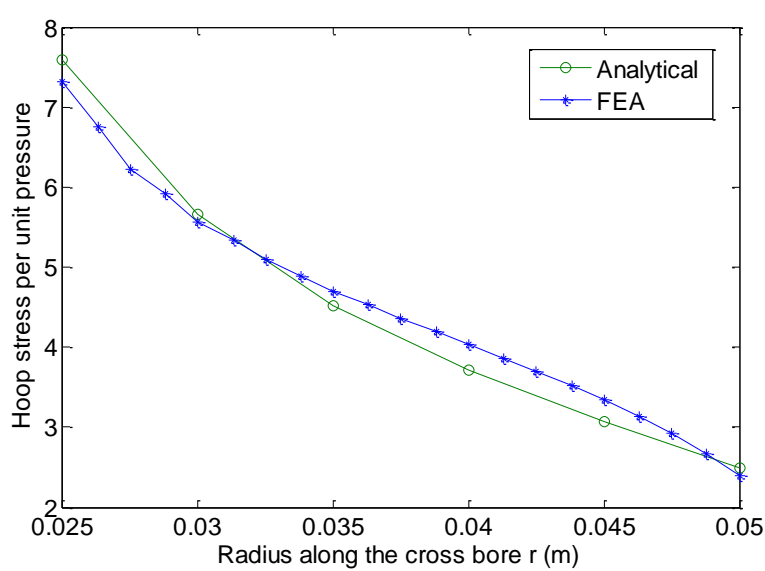

Figure 5: $\mathrm{K}=2.0 \mathrm{CB}=0.7$ 


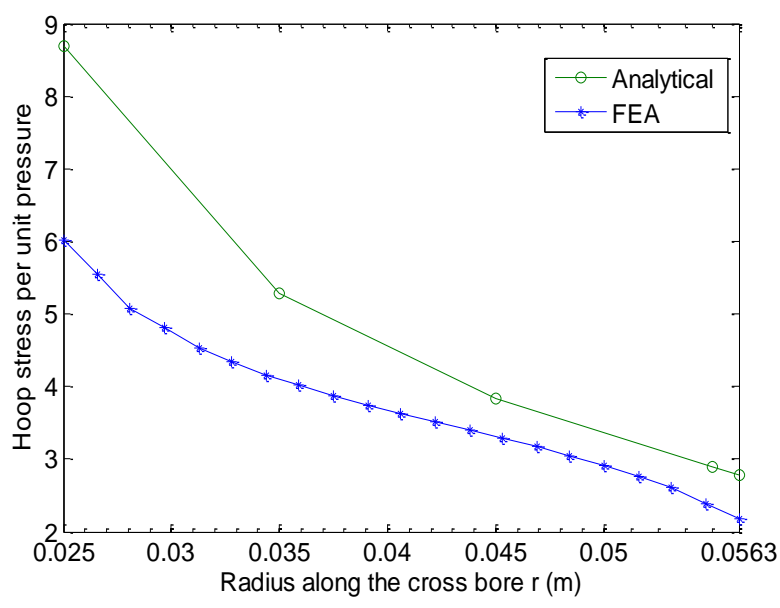

Figure 6: $\mathrm{K}=2.25 \mathrm{CB}=0.7$

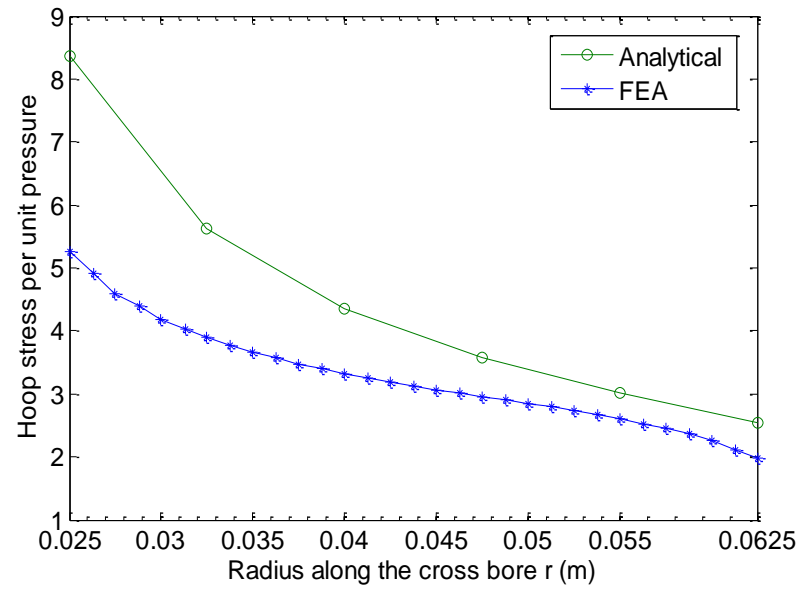

Figure 7: $\mathrm{K}=2.5 \mathrm{CB}=0.7$

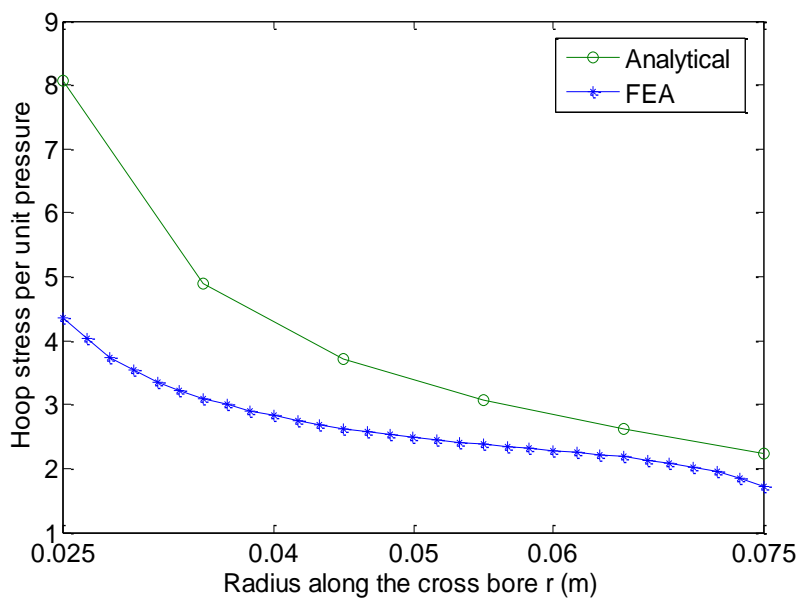

Figure 8: $K=3.0=0.7$

Figures 2 - 8: Hoop stress distribution per unit pressure for various thickness ratios along a radial circular cross bore, having cross bore to main bore size ratio of 0.7 .

As illustrated in figures 2-8, the magnitudes of hoop stresses at the cross bore intersection were high and were seen to reduce gradually towards the outside surface of the cylinder. Similar stress patterns to those given by Lame's theory in plain cylinders analyses were exhibited in the aforementioned illustrations.

The results of hoop stresses given by the two approaches only converged when $K=1.75$ and 2.0 as illustrated in Figures 4 and 5 , indicating a possibility of a stress transition point. Other thickness ratios had notably high disparities at the intersection ranging from $19 \%$ to $86 \%$ for $\mathrm{K}=1.5$ and 3.0 , respectively. Nonetheless, the rate of disparity in hoop stress distribution reduced towards the outer surface of the cylinder. In fact, for cylinders with $\mathrm{K}=2.25,2.5$ and 3.0 the inconsistency in stress distribution ceased beyond the radial distance of $0.045 \mathrm{~m}$ from the intersection.
Beyond the thickness ratio of 2.25 , the magnitude of hoop stress distribution predicted by the analytical method along the transverse edge of the cross bore was higher than that of FEA method. This occurrence signified a possibility of yielding of the pressure vessel material.

Most of the studies reviewed in the literature did not investigate cross bores with a size ratio of 0.7. Geerden (1972) studied cross bores with size ratios ranging from 0.125 to 0.667 . However, the author indicated that the solutions give inaccurate results beyond size ratios of 0.667 . Therefore, extrapolation of the results could not be done.

\section{Cross bore to main bore ratio of 0.85}

Results of high pressure vessels with a main bore to cross bore size ratio of 0.85 are presented in figures $9-15$ for $\mathrm{K}=1.4,1.5$, 1.75, 2.0, 2.25, 2.5 and 3.0. 
International Journal of Engineering Research and Technology. ISSN 0974-3154, Volume 13, Number 10 (2020), pp. 3048-3054

(C) International Research Publication House. https://dx.doi.org/10.37624/IJERT/13.10.2020.3048-3054

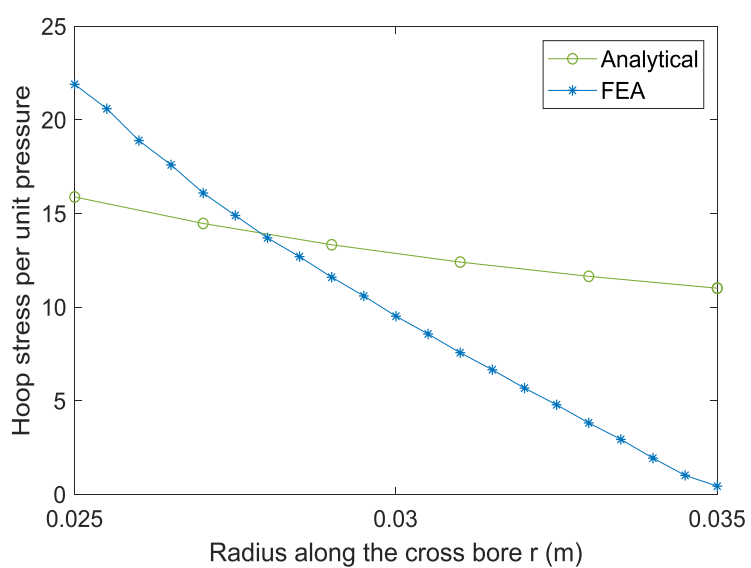

Figure 9: $\mathrm{K}=1.4 \mathrm{CB}=0.85$

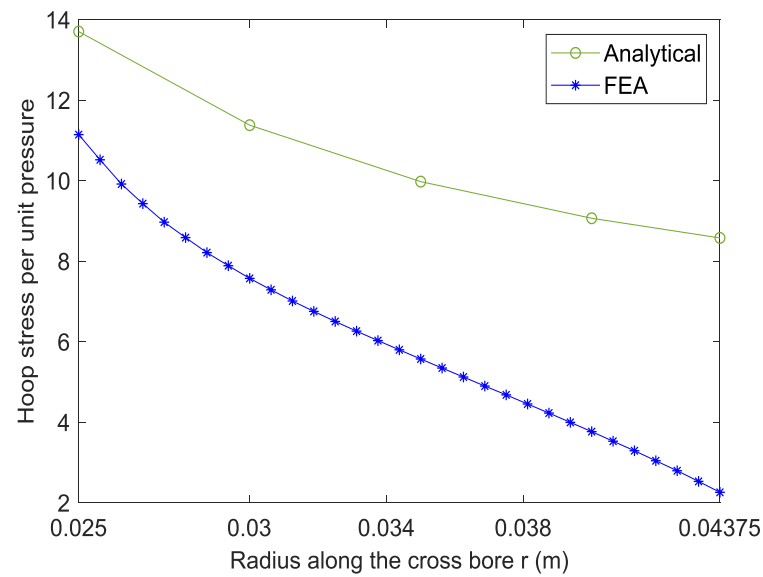

Figure 11: $\mathrm{K}=1.75 \mathrm{CB}=0.85$

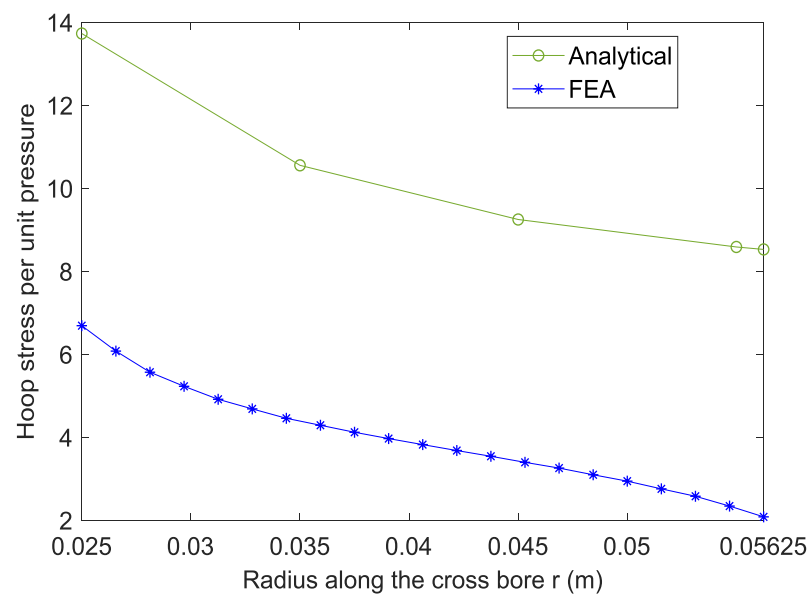

Figure 13: $\mathrm{K}=2.25 \mathrm{CB}=0.85$

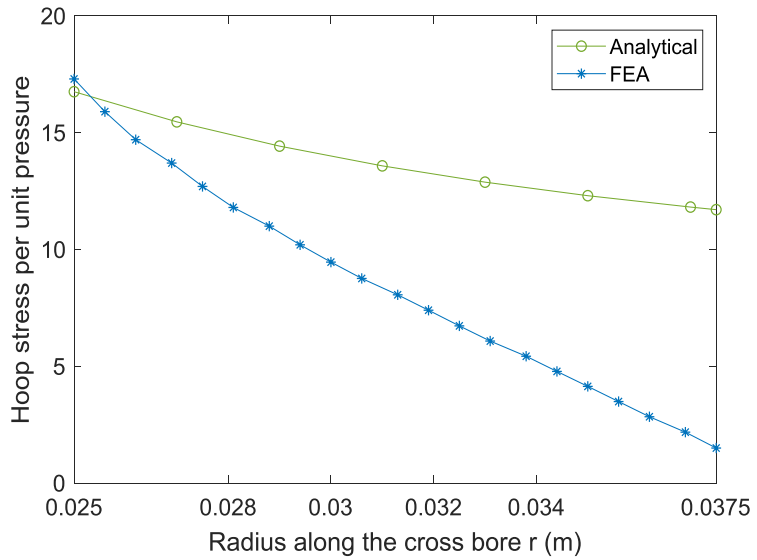

Figure 10: $K=1.5 \mathrm{CB}=0.85$

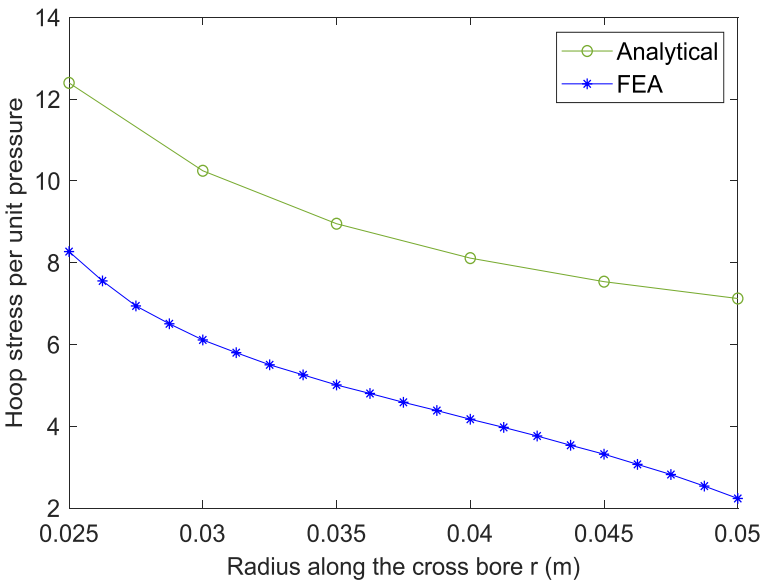

Figure 12: $\mathrm{K}=2.0 \mathrm{CB}=0.85$

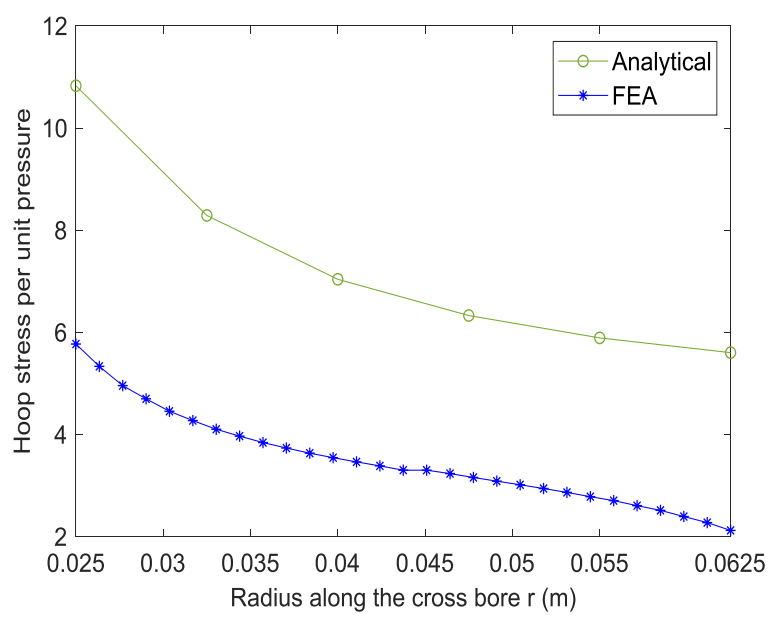

Figure 14: $K=2.5 \mathrm{CB}=0.85$ 
International Journal of Engineering Research and Technology. ISSN 0974-3154, Volume 13, Number 10 (2020), pp. $3048-3054$

(C) International Research Publication House. https://dx.doi.org/10.37624/IJERT/13.10.2020.3048-3054

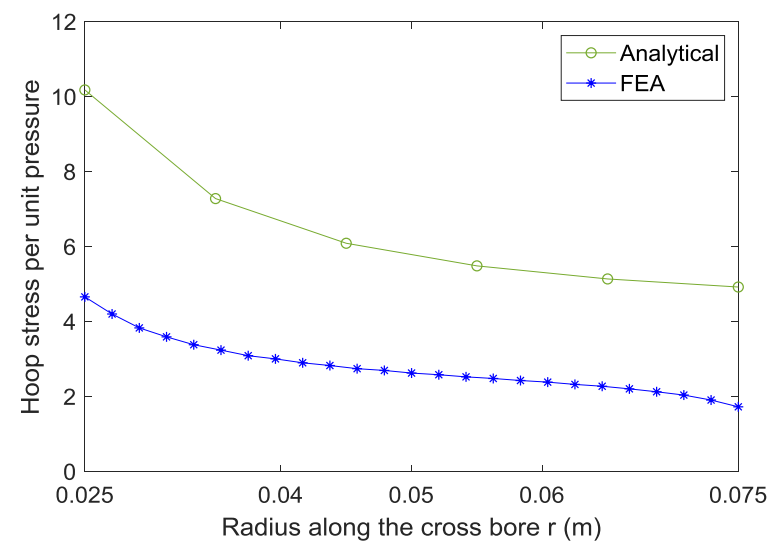

Figure 15: $\mathrm{K}=3.0 \mathrm{CB}=0.85$

Figures 9-15: Hoop stress distribution per unit pressure for various thickness ratios along a radial circular cross bore, having a cross bore to main bore size ratio of 0.85 .

As observed in Figures 9 and 10, the two methods predicted equal stress magnitudes at radius $0.027 \mathrm{~m}$ and $0.0256 \mathrm{~m}$ for $\mathrm{K}$ $=1.4$ and 1.5, respectively. Thereafter, analytical method predicted high hoop stress magnitudes. For the other thickness ratios, the magnitude of hoop stresses predicted by the analytical method along the transverse edge of the cross bore were higher than those of FEA method. This occurrence is an indication of possibility of material yielding taking place

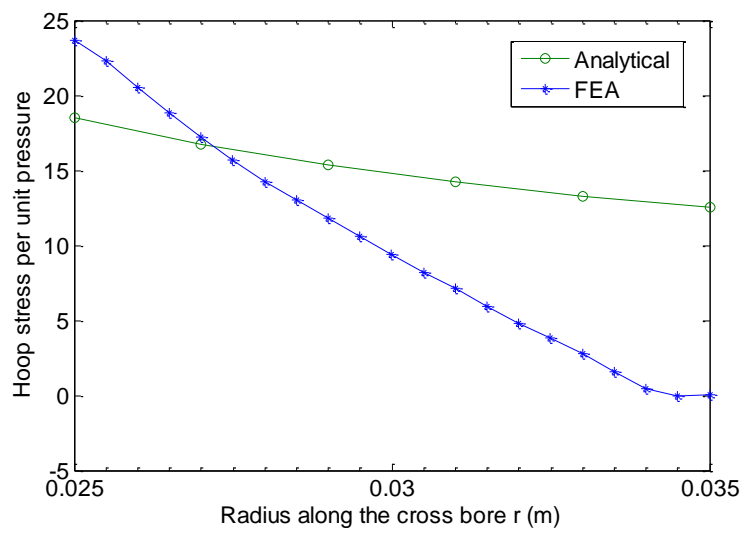

Figure 16: $\mathrm{K}=1.4 \mathrm{CB}=1.0$

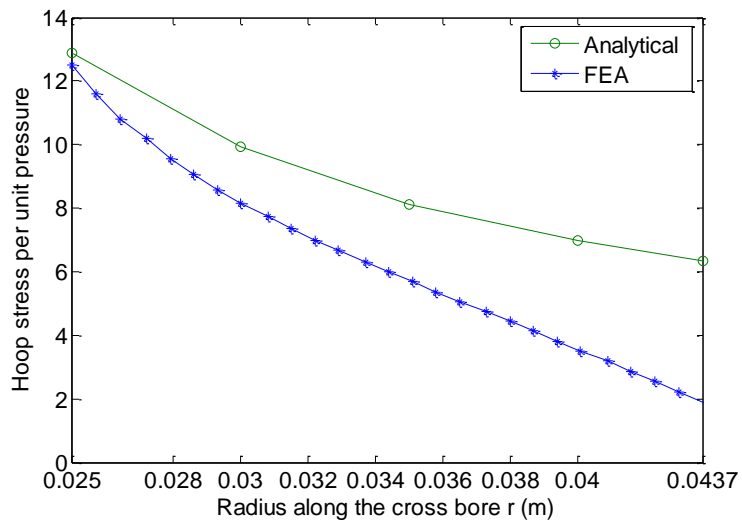

Figure 18: $\mathrm{K}=1.75 \mathrm{CB}=1.0$ whenever the thickness ratio is equal or greater than 1.75 . Though, the effects of yielding process were captured by FEA method only.

Similar to the cross bore to main bore ratio of 0.7 , there were no previous liable studies for effective comparison of these results.

\section{Cross bore to main bore ratio of 1.0}

Results of high pressure vessels with a main bore to cross bore size ratio of 1.0 are presented in figures $16-22$ for $\mathrm{K}=1.4,1.5$, $1.75,2.0,2.25,2.5$ and 3.0.

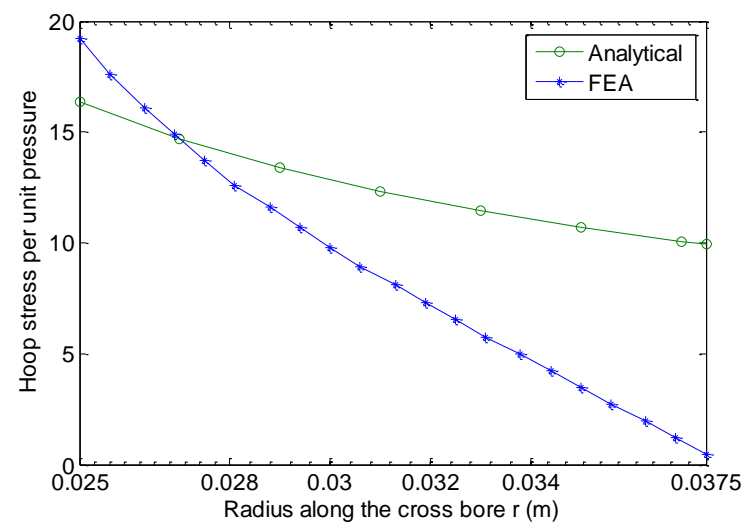

Figure 17: $\mathrm{K}=1.5 \mathrm{CB}=1.0$

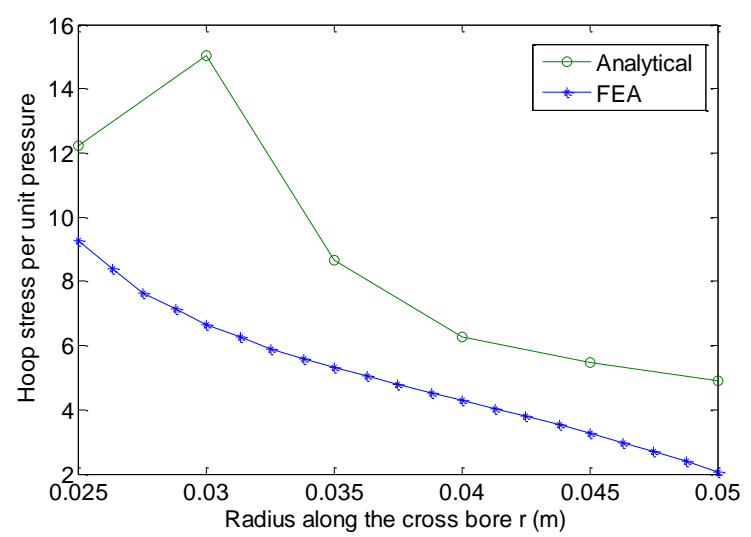

Figure 19: $\mathrm{K}=2.0 \mathrm{CB}=1.0$ 


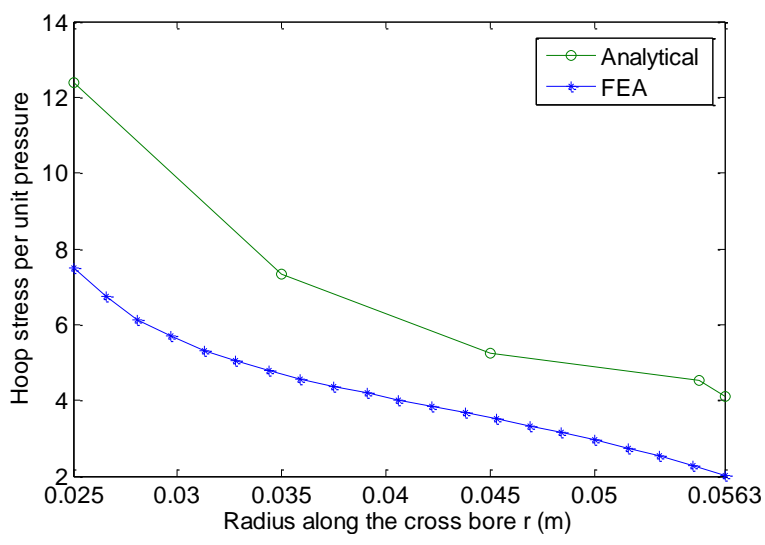

Figure 20: $\mathrm{K}=2.25 \mathrm{CB}=1.0$

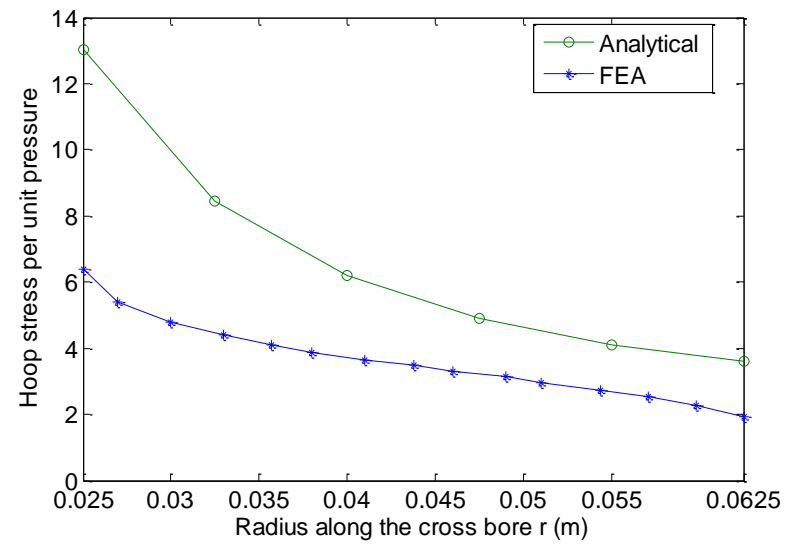

Figure 21: $\mathrm{K}=2.5 \mathrm{CB}=1.0$

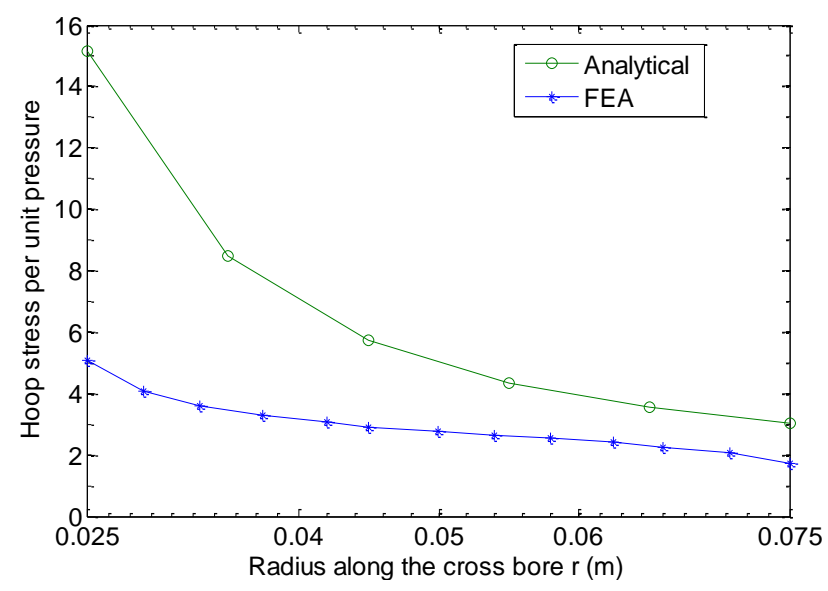

Figure 22: $\mathrm{K}=3.0 \mathrm{CB}=1.0$

Figures 16-22: Hoop stress distribution per unit pressure for various thickness ratios along a radial circular cross bore, having a cross bore to main bore size ratio of 1.0 .

For thickness ratios of $\mathrm{K}=1.4$ and 1.5 , the FEA approach gave higher stresses than the developed analytical method in the region near the cross bore intersection. However, at a radius of $0.0275 \mathrm{~m}$, the two methods predicted the same stress. After which, the analytical method predicted higher stresses than the FEA method, as shown in Figures 16 and 17. It was also noted that as the thickness ratio increased, the analytical method predicted slightly higher stress values as illustrated in Figures 20 to 21 . Except for $K=2.0$, the stress distribution along the thickness was seen to reduce gradually from the cross bore intersection towards the outside surface of the cylinder. In $\mathrm{K}=$ 2.0, the hoop stress increased sharply after the intersection to a peak value of 15.04 at $0.03 \mathrm{~m}$ from the intersection. After this peak value, the hoop stress began to fall gradually towards the outside surface of the cylinder. Generally, it was observed that the inconsistency in stress distribution reduced towards the outside surface of the cylinder specifically for $\mathrm{K}=2.0,2.25$, 2.5 and 3.0 values.

The magnitudes of hoop stresses given by the cross bore size ratio of 1.0 were higher than those of 0.7 and 0.85 cross bore sizes presented in the previous sections. This observation signified that the hoop stress at the intersection, increases with the increase of the cross bore size. This observation further confirmed that, the structural stiffness of the cylinder depends on the cross bore size. Only, results of $\mathrm{K}=1.75$ predicted by the two methods were within the acceptable error margin of $5 \%$. Other thickness ratios gave error margins exceeding $15.7 \%$. Fessler and Lewin (1956) studied a similar cross bore for $\mathrm{K}=2$ using both the analytical and experimental analyses. They reported magnitudes of hoop stress per unit pressure of 3.167 and 5.034 for analytical and experimental approaches, respectively. On the other hand, the presented study gave stress magnitudes of 12.222 and 9.276 per unit pressure for the same cross bore size. The values by Fessler and Lewin (1956) study were found to be lower than those presented in this study. Probably due to the use of different assumptions associated with experimental shortcomings especially during the determination of magnitude of principal stresses.

Similar to the cross bore to bore ratio of 0.85 discussed in the previous section, FEA method predicted lower hoop stresses than analytical method beyond thickness ratio of 1.75 . This occurrence was attributed to yielding of pressure vessel due to the tremendous increase of stresses. Usually, stresses along the large cross bores increase rapidly until the yield point of the material is reached. This yielding of the material results to permanent deformation leading to reduction of stresses. Unlike 
the theoretical method, the FEA method captured the yielding process of the vessel an occurrence attributed to the nature of how FEA solutions are generated. The solution of FEA method takes place at the gauss points and then extrapolated to the nodes at the surface. On the hand, the developed analytical solution could erroneously predict elastic hoop stresses despite the material of pressure vessel undergoing yielding.

\section{CONCLUSION}

(1) Only, at thickness ratios of 1.75 and 2.0 for bore ratio of 0.7 were the hoop stresses predicted by the two approaches converged. An occurrence that was attributed to yielding of the pressure vessels.

(2) Yielding of pressure vessels due to the introduction of large cross bore with bore ratio of 0.7 was seen to start from the thickness ratio of 2.25 and beyond. Similarly, that of bore ratios of 0.85 and 1.0 commenced from thickness ratio of 1.75 .

\section{ACKNOWLEDGEMENTS}

This work was supported by the Department of Mechanical Engineering, Vaal University of Technology, South Africa and Eskom Company.

\section{REFERENCES}

[1] Fessler, H. and Lewin, B. H. (1956), "Stress distribution in a tee-junction of thick pipes", British journal of applied physics, Vol. 7, pp. 76-79.

[2] Gerdeen J. C. (1972), “Analysis of stress concentration in thick cylinders with sideholes and crossholes", Trans. ASME, Journal Engineering Industry, No. 94, pp. 815823.

[3] Masu, L. M. (1989), "The effect of cross bore geometry on the strength of pressure vessels", PhD thesis, University of leeds.

[4] Nziu, P. K. (2018), "Optimal geometric configuration of a cross bore in high pressure vessels", Doctorate thesis, Vaal University of Technology

[5] Nziu, P.K. and Masu, L. M. (2019a) "Formulae for predicting stress concentration factors in flat plates and cylindrical pressure vessels with holes: A review", International journal of mechanical and production engineering research and development, ISSN 2249-6890, 2019, Vol. 9, issue 5, pp. 753-770, doi: 10.24247/ ijmperdoct 201967

[6] Nziu, P.K. and Masu, L. M. (2019b) Formulae to predict hoop stresses along the transverse XY plane of a small radial circular cross bore in thick cylinders, International journal of mechanical \& production engineering research and development" ISSN 2249-6890/2249-8001, Vol.9, issue 6, pp 707-724, doi: 10.24247/ijmperddec201960

[7] Nziu, P.K. and Masu, L. M. (2020) "Elastic strength of high pressure vessels with an offset elliptical cross bore", International journal of mechanical and production engineering research and development, ISSN 2249-6890, 2019, Vol. 10, issue 3, pp. 4897-4914, doi: 10.24247/ ijmperdjun 20200464 